\title{
Comparative Study of Antidiabetic Activity and Oxidative Stress Induced by Zinc Oxide Nanoparticles and Zinc Sulfate in Diabetic Rats
}

\author{
Ali Nazarizadeh ${ }^{1,2}$ and Siamak Asri-Rezaie ${ }^{1}$
}

Received 22 May 2015; accepted 24 August 2015; published online 8 September 2015

\begin{abstract}
In the current study, antidiabetic activity and toxic effects of zinc oxide nanoparticles ( $\mathrm{ZnO})$ were investigated in diabetic rats compared to zinc sulfate $\left(\mathrm{ZnSO}_{4}\right)$ with particular emphasis on oxidative stress parameters. One hundred and twenty male Wistar rats were divided into two healthy and diabetic groups, randomly. Each major group was further subdivided into five subgroups and then orally supplemented with various doses of $\mathrm{ZnO}(1,3$, and $10 \mathrm{mg} / \mathrm{kg})$ and $\mathrm{ZnSO}_{4}(30 \mathrm{mg} / \mathrm{kg}$ ) for 56 consecutive days. $\mathrm{ZnO}$ showed greater antidiabetic activity compared to $\mathrm{ZnSO}_{4}$ evidenced by improved glucose disposal, insulin levels, and zinc status. The altered activities of erythrocyte antioxidant enzymes as well as raised levels of lipid peroxidation and a marked reduction of total antioxidant capacity were observed in rats receiving $\mathrm{ZnO}$. $\mathrm{ZnO}$ nanoparticles acted as a potent antidiabetic agent, however, severely elicited oxidative stress particularly at higher doses.
\end{abstract}

KEY WORDS: antioxidant enzymes; diabetes; nanoparticle; oxidative stress; zinc.

\section{INTRODUCTION}

Diabetes mellitus is a metabolic disorder characterized by insufficiency of secretion or action of endogenous insulin resulting in the elevation of blood glucose and numerous other complications (1). The disease is one of the most important public concerns. According to the latest report of the International Diabetes Federation (IDF), the number of people with diabetes is set to rise beyond 592 million in the next 25 years. Unfortunately, $47 \%$ of the population goes undiagnosed and progresses toward diabetic complications unaware (2).

It seems that the homoeostasis of trace elements can be disrupted by diabetes mellitus (3). It has been claimed that imbalances of micronutrients such as copper, chromium, manganese, iron, nickel, zinc, ascorbic acid, and vitamin E play a crucial role in upsetting normal glucose metabolism and progression of diabetes (4-6).

Zinc $(\mathrm{Zn})$ is a trace element and the most abundantly found mineral in all human tissues and tissue fluids, after iron (7). A wide range of biological activities such as cell division (8), immune responses regulation $(9,10)$, epithelial cell integrity $(11)$,

\footnotetext{
Highlights

- Zinc oxide nanoparticles act as a potent antidiabetic agent.

- Zinc oxide nanoparticles instigate oxidative stress in diabetic and non-diabetic rats.

- Zinc sulfate protects against oxidative stress in diabetic rats.

${ }^{1}$ Department of Clinical Pathology and Internal Medicine, Faculty of Veterinary Medicine, Urmia University, P.O. Box 1177, Urmia, West Azerbaijan, Iran.

${ }^{2}$ To whom correspondence should be addressed. (e-mail: dr_alinazarizadeh@yahoo.com)
}

and the proper function of more than 300 enzymes from all enzyme families $(12,13)$ are tightly correlated with zinc.

In 1934, it was demonstrated that zinc is a part of insulin crystal (14). Since then, a clinical association has been assumed among zinc, insulin, and diabetes. Numerous studies have been trying to elucidate the precise role of zinc in pathophysiology of diabetes mellitus to date.

In the $\beta$ cell granules, the insulin molecule forms polymers and also complexes with zinc (15). Moreover, zinc has an active role in the secretion of insulin from pancreatic cells (16).

The antidiabetic and insulin-like effects of zinc have been proven in several in vitro and in vivo studies; however, the molecular mechanisms responsible for the insulin-like effects of zinc have not yet been completely understood (7). A growing number of evidence show that zinc can interact with several components of insulin signaling pathways and thus regulate glucose metabolism (7). It has been demonstrated that zinc enhances the phosphorylation of insulin receptor Bsubunit (17). Moreover, it effectively stimulates phosphatidyl inositol 3-kinase (PI3-K) and activates protein kinase B (PKB) (18-21).

Due to the insulin-like effects of zinc and its crucial role in pathophysiology of diabetes, zinc supplementation is a highly necessary strategy for the treatment of diabetic patients. Therefore, the development of such therapies with ability to improve zinc imbalance during the ailment is the issue of considerable interest to scientists. Several zinc complexes have been synthesized and evaluated in various studies some of which are commercially available for their beneficial effects. Zinc sulfate $\left(\mathrm{ZnSO}_{4}\right)$ is an inorganic salt of zinc which is widely prescribed as a supplement or for the treatment of a number of diseases. 
Nanomaterials are at the leading edge of the rapidly developing field of nanotechnology. Their unique sizedependent properties make these materials superior and indispensable in many areas of human activity (22). Nanoparticles are widely used in cosmetics, pigments and coatings, electronic devices, and catalysts (23). The similar size of nanoparticles and biomolecules such as proteins and polynucleic acids provide a wide utilization of these materials in biology and medicine (24). Moreover, because of their ultra-small size, they can easily cross through biological membranes and therefore can be highly absorbed by the digestive system. Such characteristics have been eventuated in the utilization of nanoparticles via oral root. Although impressive from the perspective of material science, the novel properties of nanoparticles could lead to adverse biological effects with the potential to create toxicity (25). In fact, there are a growing number of studies which indicate toxicity of nanoparticles by various mechanisms including generation of reactive oxygen species (ROS) in particular (26-29).

Among many kinds of nanoparticles, zinc oxide nanoparticles $(\mathrm{ZnO})$ are important industrial materials and a large amount of $\mathrm{ZnO}$ nanoparticles are produced (30). In previous years, $\mathrm{ZnO}$ nanoparticles as a novel agent in order for zinc delivery have been synthesized and assessed for their possible antidiabetic effects in streptozotocin-induced diabetic rats $(31,32)$. Although the potent antidiabetic activity of $\mathrm{ZnO}$ was observed in these studies, the influence of this nanoparticle on oxidative stress parameters was not fully determined. Additionally, the therapeutic efficacy of this nanoparticle has not yet been investigated in comparison with its bulk counterparts. Therefore, the present study was conducted to evaluate the undesired effects of $\mathrm{ZnO}$ in diabetic rats and a comparison was also performed between the nanoparticle and its respective salt (zinc sulfate) with a particular emphasis on oxidative stress parameters.

\section{MATERIALS AND METHODS}

\section{Reagents and Chemicals}

Ultra-pure ( $\geq 99 \%$ ), high-quality zinc oxide nanoparticles (80-100 $\mathrm{nm}$ ) were purchased from US Research Nanomaterials, Inc, USA (stock\# us3555). Streptozotocin (STZ) used for induction of diabetes in rats was procured from Sigma-Aldrich (Sigma, St. Louis, MO, Laviola, USA). Zinc sulfate dihydrate $\left(\mathrm{ZnSO}_{4} * 2 \mathrm{H}_{2} \mathrm{O}\right)$ was obtained from Merck Germany (containing $33.11 \%$ zinc). Sodium citrate buffer solution $(\mathrm{pH}=4.5)$ was prepared using high-quality materials.

\section{Animals}

One hundred and twenty pathogen-free male Wistar rats (7-8 weeks, 180-220 g) were obtained from Urmia University Laboratory Animal Center, Faculty of Veterinary Medicine, Urmia, Iran. The animals were maintained in a standard specific pathogen-free environment at a temperature of $23 \pm 2^{\circ} \mathrm{C}$ and controlled humidity $(60 \pm 10 \%)$, under a 12:12-h light-dark cycle. Rats were fed distilled water and a standard diet containing $22.12 \mathrm{mg}$ of zinc (per kilogram of dried material) ad libitum (33). All rats were acclimatized to their new surroundings for 1 week prior to the experimental procedures. Oral dosing was carried out using an 18-gauge oral feeding needle.

\section{Ethics}

All of the experiments involving laboratory animals were approved by Urmia Animal Care and Use Committee, and all procedures of the current experiment were performed at the animal housing department, Faculty of Veterinary Medicine.

\section{Experimental Protocols and Grouping}

The animals were divided into two major healthy and diabetic groups, randomly. Diabetes was induced according to the previously described procedure (34) in 60 animals. Briefly, the rats in the diabetic groups were fasted overnight, then injected intraperitoneally (i.p.) with freshly prepared STZ in citrate buffer $(0.1 \mathrm{M}, \mathrm{pH} 4.5)$ at a single dose of $50 \mathrm{mg} / \mathrm{kg}$, body weight. Hyperglycemia was confirmed by the elevated glucose levels in serum, determined at $72 \mathrm{~h}$ after injection of the STZ, using a digital glucometer (Elegans, Germany). The animals were considered diabetic if the blood glucose level was $>250 \mathrm{mg} / \mathrm{dl}$. The diabetic rats were further subdivided into five subgroups of 12 animals each: (I) diabetic control group - they did not receive any treatment. (II-IV) Diabetic $+\mathrm{ZnO}$ - the animals in these groups were treated with zinc oxide nanoparticles in three different doses of 1,3 , and $10 \mathrm{mg} / \mathrm{kg}$ orally by gavage. (V) Diabetic $+\mathrm{ZnSO}_{4}$ - the animals in this group were given $30 \mathrm{mg} / \mathrm{kg}$ of zinc sulfate, $2 \mathrm{H}_{2} \mathrm{O}$ orally by gavage (equally $10 \mathrm{mg} / \mathrm{kg}$ zinc). The same grouping was performed for the other 60 healthy rats. The oral dosing was performed once a day from the fourth day after IP injection of citrate buffer and STZ for 56 consecutive days. The selected doses of the nanoparticle were based on the previous study in which repeated oral dosing and toxicity of $\mathrm{ZnO}$ were well established (31). According to the manual of the commercial supplier, zinc oxide nanoparticles consist of $80.34 \%$ zinc and $19.6 \%$ oxygen, so the selected doses of the nanoparticle deliver approximately $8.03,2.41$, and $0.8 \mathrm{mg}$ of zinc, respectively. Zinc sulfate dosage was designed according to the pervious study in which zinc dose (as zinc sulfate) was $30 \mathrm{mg} / \mathrm{kg}$ for 42 days (35). The selected dose of zinc sulfate, $2 \mathrm{H}_{2} \mathrm{O}$ by estimation $33.11 \%$ zinc in it, delivers approximately $10 \mathrm{mg}$ zinc.

$\mathrm{ZnO}$ nanoparticles were suspended in deionized water at a concentration of $10 \mathrm{mg} / \mathrm{ml}$. Prior to each treatment, in order to break the agglomerate and ensure a uniform suspension, all nanoparticle samples were sonicated four times intermittently, using sonicator probe (Branson Sonifier, USA) at $30 \mathrm{~W}$ for $10 \mathrm{~min}$ ( $2.5 \mathrm{~min}$ on and $30 \mathrm{~s}$ off) and diluted to prepare the different nanoparticle concentrations.

\section{Blood Sampling}

Blood sampling was performed at the different intervals of 1,4 , and 8 weeks. At the each time point, four animals from every group were deeply anesthetized with IP injection of a mixture of ketamine $(150 \mathrm{mg} / \mathrm{kg})$ and xylazine $(15 \mathrm{mg} / \mathrm{kg})$ (34), and then blood samples were collected from the heart (almost $4 \mathrm{ml}$ ) in heparinized and non-heparinized tubes. The 
non-heparinized blood was allowed to coagulate and centrifuged (3000 rpm for $10 \mathrm{~min}$ ) and the separated serum samples transferred to Eppendorf tubes and stored at $-80^{\circ} \mathrm{C}$ until analysis. Catalase and glutathione peroxidase activities were determined in serum and whole blood, respectively. For evaluation of superoxide dismutase activity, heparinized blood samples were centrifuged, plasma separated, and packed cells were washed three times with normal saline solution and then hemolysate was prepared via the addition of cold distilled water.

\section{Biochemical Assays and Analysis}

Blood glucose was evaluated according to the routine method of enzymatic colorimetric determination of glucose oxidase (GOD) using a standard assay kit (Ziest Chem Diagnostics, Iran). Rat insulin ELISA Kit (Cayman Chemical, item number 589501) was employed for determination of insulin level in serum samples. Zinc concentrations in serum samples were measured using atomic absorption spectrophotometer (Shimadzu AA-6800). Serum levels of malondialdehyde (MDA), a marker of lipid peroxidation, were evaluated as thiobarbituric acid reactive substances (TBARS) by the method of Nair and Turner (36). The activities of erythrocyte glutathione peroxidase (GSH-Px), superoxide dismutase (SOD), and catalase (CAT) were determined according to our previously described procedures (37). The assessment of total antioxidant capacity (TAC) was performed according to the kit manual (TAS test kit, Randox Laboratories Ltd. G.B.).

\section{Statistical Analysis}

All data were analyzed using SPSS software (version 19, USA) and expressed as means \pm standard deviation (SD). Analysis of variance (ANOVA) was followed by Duncan's multiple range test (DMRT) for multiple comparisons to evaluate whether values at the same time point were different between the controls and the treatment groups and two-way analysis of variance for repeated measurements with multiple comparisons. A significant difference was presumed at a $P$ value $<0.05$.

\section{RESULTS}

\section{Assessment of Blood Glucose Levels}

The effects of oral administration of $\mathrm{ZnO}$ nanoparticles and zinc sulfate on glucose levels are depicted in Tables I and II for healthy and diabetic rats, respectively. No significant change was observed by the nanoparticles in healthy rats, except for a slight reduction by the dose of $10 \mathrm{mg} / \mathrm{kg}$ on day 56 . In addition, zinc sulfate reduced blood glucose on day 28 ; however, this was not stable and was again elevated to normal range on day 56. Intraperitoneal injection of streptozotocin resulted in significant increase in blood glucose (greater than $250 \mathrm{mg} / \mathrm{dl})$. ZnO treatment decreased glucose levels in a timeand dose-dependent fashion $(P<0.01)$. Zinc sulfate also depressed glucose levels time dependently $(P<0.01)$.

\section{Assessment of Serum Insulin Levels}

Treatment with the higher doses ( 3 and $10 \mathrm{mg} / \mathrm{kg}$ ) of the $\mathrm{ZnO}$ nanoparticle gradually increased serum insulin contents in healthy rats and significantly differed at the end of experimental course compared to the control group (Table I). Induction of diabetes plummeted serum insulin content (approximately fivefold). Oral supplementation with $\mathrm{ZnO}$ nanoparticles effectively restored insulin levels particularly at the highest dose $(10 \mathrm{mg} / \mathrm{kg})$. Zinc sulfate also increased insulin contents time dependently (Table II).

\section{Assessment of Serum Zinc Levels}

Both of the treatments $\left(\mathrm{ZnO}\right.$ and $\left.\mathrm{ZnSO}_{4}\right)$ could elevate serum zinc contents in the healthy rats with a tendency toward a time-dependent fashion (Table I). Induction of diabetes significantly suppressed serum zinc levels $(P<0.01)$, and supplementation with both of the treatments could improve zinc concentrations time dependently. The highest dose of the nanoparticles $(10 \mathrm{mg} / \mathrm{kg})$, however, was found to be more effective in diabetic animals (Table II).

\section{Assessment of Serum Malondialdehyde Levels}

The results of serum malondialdehyde contents are represented in Tables I and II. ZnO nanoparticles treatment to both healthy and diabetic rats elevated MDA levels particularly at the highest dose $(10 \mathrm{mg} / \mathrm{kg})$ compared to respective control groups. Further, IP injection of STZ by inducing diabetes mellitus and hyperglycemia raised MDA levels (almost twofold). Zinc sulfate administration to healthy rats did not significantly change MDA contents; but, in diabetic ones reduced MDA production $(P<0.05)$.

\section{Assessment of RBC Glutathione Peroxidase Activity}

$\mathrm{ZnO}$ treatment with higher doses (3 and $10 \mathrm{mg} / \mathrm{kg}$ ) to both healthy and diabetic rats significantly reduced GSH-Px activity in a time-dependent manner compared to respective control groups (Tables III and IV). In contrast, the lower dose $(1 \mathrm{mg} / \mathrm{kg})$ of the nanoparticle increased the enzyme activity in both of the groups; however, this increment was not stable and a gradual suppression was observed during the course of the study. The induction of diabetes also depressed the enzyme activity. Zinc sulfate treatment to healthy rats did not have a significant effect on GSH-Px activity, except for a slight rise on day 7 in comparison with healthy control group; however, in diabetic ones, the activity was restored close to its normal limit (Table IV).

\section{Assessment of RBC Catalase Activity}

$\mathrm{ZnO}$ administration to healthy rats resulted in reduction of catalase activity at the end of the experimental period with a tendency toward a dose-dependent fashion (Table III). Induction of diabetes tremendously depressed catalase activity (approximately fourfold). Treatment with $\mathrm{ZnO}$ nanoparticles particularly at the lower dose $(1 \mathrm{mg} / \mathrm{kg})$ could increase the activity compared to diabetic control (Table IV). Zinc sulfate also could elevate the enzyme activity. 


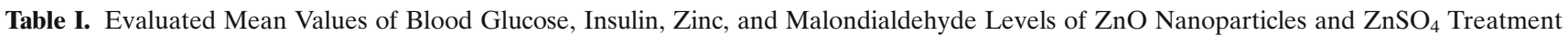
Healthy Rats

\begin{tabular}{|c|c|c|c|c|c|c|c|}
\hline Parameter & $\begin{array}{l}\text { Groups } \\
\text { Time }\end{array}$ & $\begin{array}{l}\text { Healthy rats } \\
\text { control }\end{array}$ & $\begin{array}{l}\text { Healthy rats } \\
\mathrm{ZnO} 1 \mathrm{mg}\end{array}$ & $\begin{array}{l}\text { Healthy rats } \\
\text { ZnO } 3 \text { mg }\end{array}$ & $\begin{array}{l}\text { Healthy rats } \\
\mathrm{ZnO} 10 \mathrm{mg}\end{array}$ & $\begin{array}{l}\text { Healthy rats } \\
\mathrm{ZnSO}_{4} 30 \mathrm{mg}\end{array}$ & $P$ value \\
\hline \multirow[t]{4}{*}{ Glucose (mg/dl) } & 7 days & $86.15 \pm 8.16$ & $80.35 \pm 6.61$ & $83.66 \pm 5.30$ & $79.35 \pm 3.37$ & $81.04 \pm 2.78^{\mid}$ & 0.452 \\
\hline & 28 days & $86.33 \pm 6.36^{\mathrm{a}}$ & $68.28 \pm 6.36^{\mathrm{bc}}$ & $84.73 \pm 7.93^{\mathrm{a}}$ & $80.38 \pm 3.41^{\mathrm{ab}}$ & $73.44 \pm 4.36^{\mathrm{c} \dagger}$ & 0.002 \\
\hline & 56 days & $89.62 \pm 11.04^{\mathrm{a}}$ & $72.69 \pm 11.04^{b}$ & $84.2 \pm 8.45^{\mathrm{ab}}$ & $74.12 \pm 3.74^{\mathrm{b}}$ & $85.44 \pm 4.25^{\mathrm{a}}$ & 0.013 \\
\hline & $P$ value & 0.679 & 0.170 & 0.979 & 0.069 & 0.005 & \\
\hline \multirow[t]{4}{*}{ Insulin $(\mu \mathrm{U} / \mathrm{l})$} & 7 days & $1.94 \pm 0.14^{\mathrm{ab}}$ & $1.98 \pm 0.08^{\mathrm{a}}$ & $1.84 \pm 0.15^{\mathrm{ab} \mid}$ & $1.69 \pm 0.21^{\mathrm{ab} \mid}$ & $1.61 \pm 0.18^{\mathrm{b} \mid}$ & 0.023 \\
\hline & 28 days & $2.01 \pm 0.10^{\mathrm{a}}$ & $2.27 \pm 0.10^{\mathrm{a} \dagger}$ & $2.12 \pm 0.13^{\mathrm{a} \mid \dagger}$ & $2.10 \pm 0.19^{\mathrm{a} \dagger}$ & $1.78 \pm 0.07^{\mathrm{b} \mid}$ & 0.001 \\
\hline & 56 days & $2.00 \pm 0.13^{\mathrm{a}}$ & $2.17 \pm 0.13^{\mathrm{a}^{\dagger}}$ & $2.32 \pm 0.17^{\mathrm{b} \dagger}$ & $2.32 \pm 0.22^{\mathrm{b} \dagger}$ & $2.01 \pm 0.08^{\mathrm{a} \dagger}$ & 0.012 \\
\hline & $P$ value & 0.669 & 0.001 & 0.006 & 0.007 & 0.006 & \\
\hline \multirow[t]{4}{*}{$\operatorname{Zinc}(\mu \mathrm{g} / \mathrm{dl})$} & 7 days & $69.93 \pm 4.24^{\mathrm{a}}$ & $79.01 \pm 1.21^{\mathrm{bd} \mid}$ & $84.38 \pm 2.65^{\mathrm{b}}$ & $96.46 \pm 0.62^{\mathrm{c} \mid}$ & $78.41 \pm 2.05^{\mathrm{d} \mid}$ & 0.001 \\
\hline & 28 days & $68.88 \pm 6.26^{\mathrm{a}}$ & $92.42 \pm 6.11^{\mathrm{b} \dagger}$ & $89.02 \pm 1.75^{\mathrm{b}}$ & $104.67 \pm 0.92^{\mathrm{c}^{\dagger}}$ & $103.01 \pm 2.97^{\mathrm{c} \dagger}$ & 0.001 \\
\hline & 56 days & $71.16 \pm 4.15^{\mathrm{a}}$ & $94.50 \pm 5.12^{\mathrm{b} \dagger}$ & $88.95 \pm 2.82^{\mathrm{b}}$ & $105.94 \pm 2.52^{\mathrm{c} \dagger}$ & $110.43 \pm 4.39^{\mathrm{c} \neq}$ & 0.001 \\
\hline & $P$ value & 0.814 & 0.002 & 0.040 & 0.001 & 0.001 & \\
\hline \multirow[t]{4}{*}{ MDA (nmol/l) } & 7 days & $1.10 \pm 0.07^{\mathrm{a}}$ & $1.31 \pm 0.02^{\mathrm{b} \mid}$ & $1.34 \pm 0.06^{\mathrm{b}}$ & $1.31 \pm 0.05^{\mathrm{b} \mid}$ & $0.99 \pm 0.09^{\mathrm{a}}$ & 0.001 \\
\hline & 28 days & $1.08 \pm 0.09^{\mathrm{a}}$ & $1.56 \pm 0.09^{\mathrm{b} \dagger}$ & $1.28 \pm 0.04^{\mathrm{c}}$ & $1.54 \pm 0.08^{\mathrm{b} \mid \dagger}$ & $1.11 \pm 0.06^{\mathrm{a}}$ & 0.001 \\
\hline & 56 days & $1.14 \pm 0.10^{\mathrm{ad}}$ & $1.50 \pm 0.11^{\text {ac } \dagger}$ & $1.38 \pm 0.07^{\mathrm{ad}}$ & $1.85 \pm 0.14^{\mathrm{c} \dagger}$ & $1.10 \pm 0.07^{\mathrm{d}}$ & 0.001 \\
\hline & $P$ value & 0.673 & 0.005 & 0.120 & 0.016 & 0.134 & \\
\hline
\end{tabular}

Means within a row with different superscript letters $(\mathrm{a}-\mathrm{d})$ denote significant differences $(P<0.01)$ with healthy control. Means within a column with different superscript characters $(\mid, \dagger, \ddagger)$ denote significant differences $(P<0.01)$ with day 7 values

$M D A$ malondialdehyde, $\mathrm{ZnO}$ zinc oxide nanoparticles

\section{Assessment of Serum Catalase Activity}

In healthy rats, $\mathrm{ZnO}$ treatment resulted in suppression of serum catalase activity compared to the control group (Table III). This reduction was more considerable for the dose $3 \mathrm{mg} / \mathrm{kg}$ of the nanoparticle on day 56 . Induction of diabetes plummeted the enzyme activity (approximately fourfold). Treatment with $\mathrm{ZnO}$ nanoparticles particularly at the dose of $3 \mathrm{mg} / \mathrm{kg}$ restored serum catalase activity time dependently. Zinc sulfate also could increase the activity (Table IV).

\section{Assessment of RBC Superoxide Dismutase Activity}

As can be seen from Tables III and IV, ZnO treatment to both healthy and diabetic rats resulted in gradual elevation of superoxide dismutase activity with a tendency toward a timeand dose-dependent manner. Induction of diabetes also increased the enzyme activity in a time-dependent fashion. Zinc sulfate administration to healthy rats did not alter the enzyme activity significantly except for a slight rise on day 56; but, in diabetic ones, it reduced SOD activity close to the normal limit.

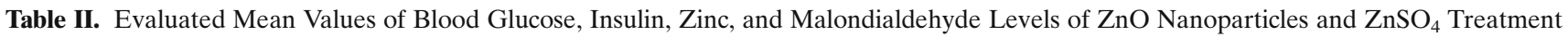
Diabetic Rats

\begin{tabular}{|c|c|c|c|c|c|c|c|}
\hline Parameter & $\begin{array}{l}\text { Groups } \\
\text { Time }\end{array}$ & $\begin{array}{l}\text { Diabetic rats } \\
\text { control }\end{array}$ & $\begin{array}{l}\text { Diabetic rats } \\
\mathrm{ZnO} 1 \mathrm{mg}\end{array}$ & $\begin{array}{l}\text { Diabetic rats } \\
\mathrm{ZnO} 3 \mathrm{mg}\end{array}$ & $\begin{array}{l}\text { Diabetic rats } \\
\mathrm{ZnO} 10 \mathrm{mg}\end{array}$ & $\begin{array}{l}\text { Diabetic rats } \\
\mathrm{ZnSO}_{4} 30 \mathrm{mg}\end{array}$ & $P$ value \\
\hline \multirow[t]{4}{*}{ Glucose (mg/dl) } & 7 days & $497.75 \pm 13.18^{a}$ & $475.35 \pm 14.26^{\mathrm{a} \mid}$ & $462.05 \pm 13.59^{\mathrm{b} \mid}$ & $468.51 \pm 20.33^{\mathrm{a} \mid}$ & $486.11 \pm 18.24^{\mathrm{a} \mid}$ & 0.024 \\
\hline & 28 days & $497.00 \pm 13.19^{\mathrm{a}}$ & $420.78 \pm 14.57^{\mathrm{b} \dagger}$ & $403.24 \pm 16.05^{\mathrm{bc} \dagger}$ & $379.59 \pm 14.31^{\mathrm{c} \dagger}$ & $427.10 \pm 18.18^{\mathrm{b} \dagger}$ & 0.002 \\
\hline & 56 days & $498.75 \pm 11.03^{\mathrm{a}}$ & $342.69 \pm 11.05^{\mathrm{b} \ddagger}$ & $304.68 \pm 18.37^{\mathrm{c} \ddagger}$ & $289.34 \pm 13.21^{\mathrm{c} \neq}$ & $356.01 \pm 16.85^{\mathrm{b} \ddagger}$ & 0.001 \\
\hline & $P$ value & 0.981 & 0.001 & 0.001 & 0.001 & 0.001 & \\
\hline \multirow[t]{4}{*}{ Insulin $(\mu \mathrm{U} / \mathrm{l})$} & 7 days & $0.36 \pm 0.07^{\mathrm{a}}$ & $0.52 \pm 0.03^{\mathrm{b}}$ & $0.55 \pm 0.06^{\mathrm{c}}$ & $0.34 \pm 0.03^{\mathrm{a}}$ & $0.32 \pm 0.04^{\mathrm{a}}$ & 0.001 \\
\hline & 28 days & $0.32 \pm 0.03^{\mathrm{a}}$ & $0.48 \pm 0.05^{\mathrm{a}}$ & $0.77 \pm 0.08^{\mathrm{b} \dagger}$ & $0.67 \pm 0.06^{\mathrm{b} \dagger}$ & $0.43 \pm 0.02^{\mathrm{a}^{\dagger}}$ & 0.001 \\
\hline & 56 days & $0.25 \pm 0.05^{\mathrm{a}^{\dagger}}$ & $0.49 \pm 0.05^{\mathrm{b}}$ & $0.87 \pm 0.09^{\mathrm{c} \dagger}$ & $1.10 \pm 0.03^{\mathrm{d} \ddagger}$ & $0.56 \pm 0.03^{\mathrm{b} \ddagger}$ & 0.001 \\
\hline & $P$ value & 0.05 & 0.677 & 0.005 & 0.001 & 0.001 & \\
\hline \multirow[t]{4}{*}{ Zinc $(\mu \mathrm{g} / \mathrm{dl})$} & 7 days & $47.55 \pm 2.78^{\mathrm{a}}$ & $64.02 \pm 2.71^{\mathrm{b} \mid}$ & $67.67 \pm 3.44^{\mathrm{b} \mid}$ & $65.46 \pm 3.77^{\mathrm{b} \mid}$ & $66.16 \pm 2.42^{\mathrm{b} \mid}$ & 0.001 \\
\hline & 28 days & $44.96 \pm 4.31^{\mathrm{a} \mid}$ & $65.79 \pm 3.40^{\mathrm{b} \mid}$ & $77.40 \pm 3.71^{\mathrm{c} \dagger}$ & $82.66 \pm 4.64^{\mathrm{c}^{\dagger}}$ & $76.85 \pm 6.03^{\mathrm{c} \dagger}$ & 0.001 \\
\hline & 56 days & $38.28 \pm 2.19^{\mathrm{a} \dagger}$ & $69.36 \pm 2.97^{\mathrm{b} \dagger}$ & $85.39 \pm 5.64^{\mathrm{c} \dagger}$ & $95.97 \pm 4.54^{\mathrm{c} \dagger}$ & $78.39 \pm 1.64^{\mathrm{bc} \dagger}$ & 0.001 \\
\hline & $P$ value & 0.008 & 0.045 & 0.001 & 0.001 & 0.003 & \\
\hline \multirow[t]{4}{*}{ MDA (nmol/l) } & 7 days & $2.71 \pm 0.09^{\mathrm{a}}$ & $2.89 \pm 0.09^{\mathrm{a}}$ & $3.13 \pm 0.06^{\mathrm{b}}$ & $3.37 \pm 0.04^{\mathrm{b}}$ & $2.65 \pm 0.24^{\mathrm{a} \mid}$ & 0.001 \\
\hline & 28 days & $2.85 \pm 0.04^{\mathrm{a} \mid}$ & $2.96 \pm 0.07^{\mathrm{ab}}$ & $3.03 \pm 0.10^{\mathrm{b}}$ & $3.47 \pm 0.05^{\mathrm{c}}$ & $2.05 \pm 0.09^{\mathrm{d} \dagger}$ & 0.001 \\
\hline & 56 days & $2.92 \pm 0.08^{\mathrm{a}^{\dagger}}$ & $3.18 \pm 0.04^{\mathrm{b} \dagger}$ & $3.12 \pm 0.09^{\mathrm{ab}}$ & $3.48 \pm 0.11^{\mathrm{c}}$ & $2.34 \pm 0.15^{\mathrm{d} \mid \dagger}$ & 0.001 \\
\hline & $P$ value & 0.014 & 0.001 & 0.258 & 0.139 & 0.003 & \\
\hline
\end{tabular}

Means within a row with different superscript letters $(\mathrm{a}-\mathrm{d})$ denote significant differences $(P<0.01)$ with diabetic control. Means within a column with different superscript characters $(\mid, \dagger, \ddagger)$ denote significant differences $(\mathrm{P}<0.01)$ with day 7 values

$M D A$ malondialdehyde, $\mathrm{ZnO}$ zinc oxide nanoparticles 


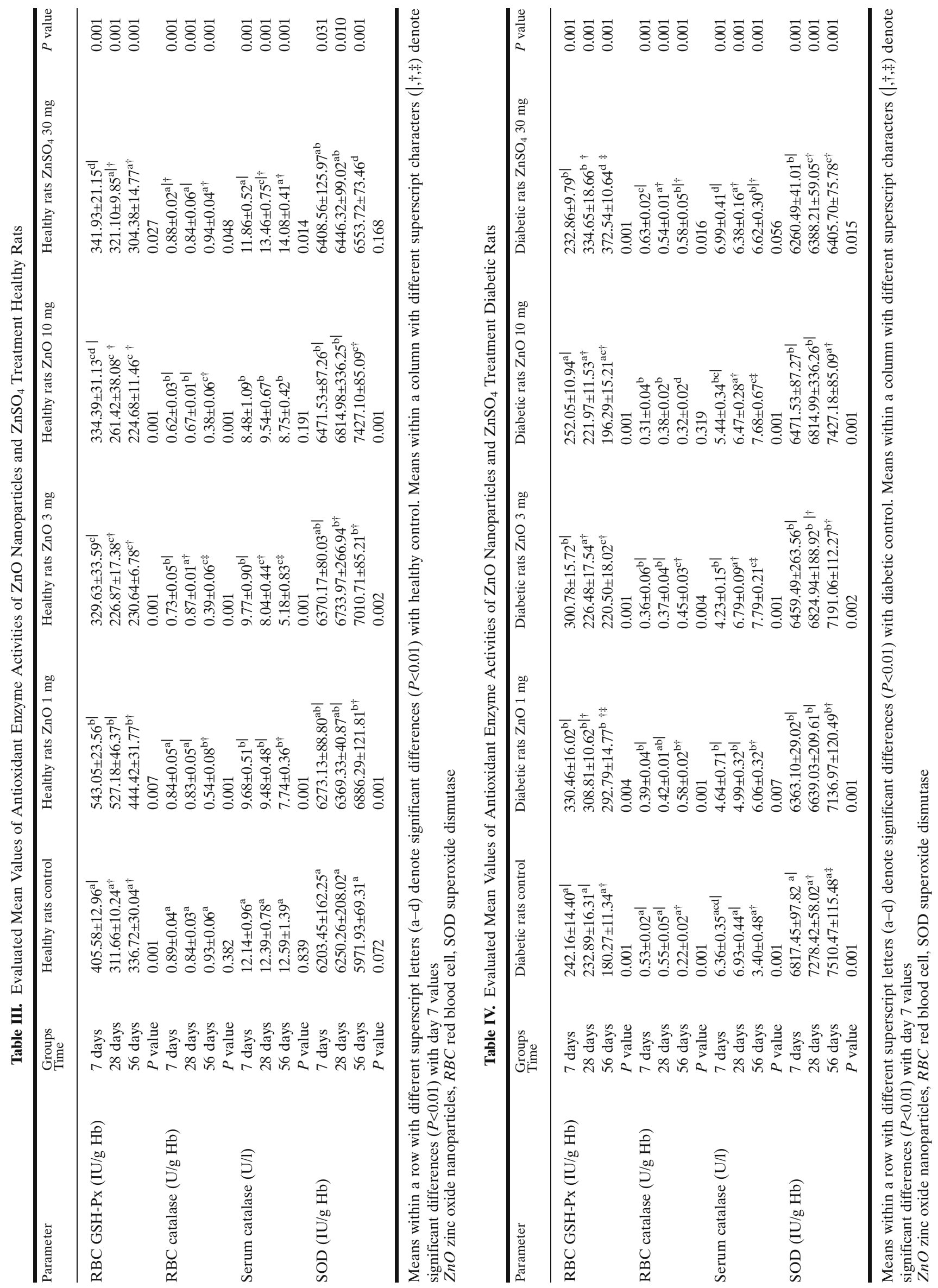




\section{Assessment of Serum Total Antioxidant Capacity}

$\mathrm{ZnO}$ administration with the lower dose $(1 \mathrm{mg} / \mathrm{kg})$ and $\mathrm{ZnSO}_{4}$ had no significant effect on serum total antioxidant capacity in healthy rats. However, the higher doses $(3,10)$ of the nanoparticle gradually decreased serum TAC with a tendency toward a time- and dose-dependent manner and significantly differed with the control group at the end of the study course (Fig. 1). Induction of diabetes significantly attenuated serum total antioxidant capacity $(P<0.01)$ in a time-dependent fashion, and treatment with nanoparticles at higher doses (3 and $10 \mathrm{mg} / \mathrm{kg}$ ) also severely suppressed TAC alike to healthy ones (Fig. 2). No significant differences were seen between the lower dose $(1 \mathrm{mg} / \mathrm{kg})$ of $\mathrm{ZnO}$ and diabetic control. Zinc sulfate application could cease the reduction of antioxidant capacity in diabetic rats.

\section{DISCUSSION}

In the present comprehensive study, effects of long-term supplementation with $\mathrm{ZnO}$ nanoparticles on antioxidant enzyme activities and oxidative stress parameters in streptozotocin induced type 1 diabetic rats were assessed. We employed previously described doses to evaluate the undesired effects of them, further; the nanoparticle therapeutic efficacy was compared to its respective salt. In previous years, several kinds of nanoparticles have been proposed as drug delivery system and some of them were evaluated for their possible curative effects $(31,32)$. Regarding increasing risk of human exposure to these nanoparticles, there is an urgent need to investigate their harmful effects. Once entering the body, nanoparticles reach blood circulation and thereby are delivered to different organs. Therefore, understanding their impact on blood components is absolutely essential.

Administration of $\mathrm{ZnO}$ nanoparticles to diabetic rats could result in improvement of blood glucose disposal and increase in insulin levels in a time- and dose-dependent fashion. These data indicated antidiabetic activity of the nanoparticles. The findings of the present study were consistent with previous reports $(31,32)$. Our experiments showed that $\mathrm{ZnO}$ nanoparticles at higher doses ( 3 and $10 \mathrm{mg} / \mathrm{kg}$ ) had a much greater antidiabetic effect compared to $\mathrm{ZnSO}_{4}$ evidenced by a marked reduction of blood glucose and increase in insulin levels. Zinc interacts with several components of insulin signaling pathway and thus regulates glucose metabolism. Others reported that $\mathrm{ZnO}$ nanoparticles increased the mRNA expression level of insulin gene and consistently observed higher expression levels of insulin receptor gene in hepatic tissues of $\mathrm{ZnO}$-receiving diabetic rats (32).

The induction of diabetes considerably reduced serum zinc contents. This is a common finding in diabetic patients and can be related to hyperzincuria (16). It is well established that zinc supplementation effectively prevents the metabolic syndrome and diabetes and its secondary complications $(13,38)$. In our study, $\mathrm{ZnO}$ treatment to diabetic rats improved serum zinc status in a time- and dose-dependent manner. With this aspect, we found that $\mathrm{ZnO}$ treatment at the higher doses ( 3 and $10 \mathrm{mg} / \mathrm{kg}$ ) was more effective compared to $\mathrm{ZnSO}_{4}$. This finding could be attributed to the size of $\mathrm{ZnO}$. Because of the extremely small dimensions, nanoparticles can easily cross through biological membranes and be accumulated in blood.

Measurement of lipid peroxidation is a gold marker of oxidative damage caused by ROS, and the assessment of MDA is a reliable method to gain such determination $(35,39)$. Highly reactive oxygen metabolites, especially

serum total antioxidant capacity levels $(\mathrm{mmol} / \mathrm{l})$ in Healthy rats with $\mathrm{ZnO}$ nanoparticles \& $\mathrm{ZnSO}_{4}$

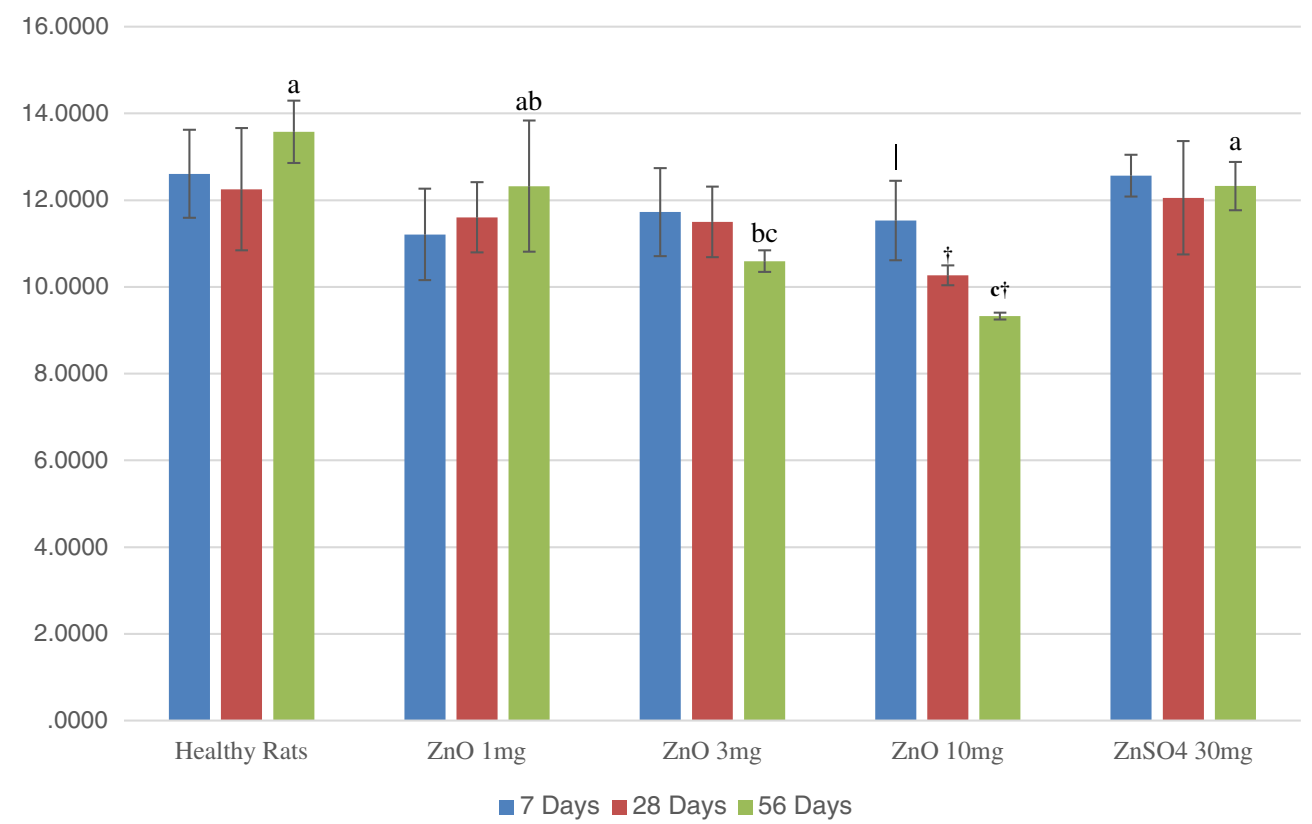

Fig. 1. Effects of $\mathrm{ZnO}$ nanoparticles and $\mathrm{ZnSO}_{4}$ on serum TAC levels (mmol/l) in healthy rats. Each bar represents mean $\pm \mathrm{SD}$ in each group. Bars within the same color carrying different superscript letters $(a-d)$ denote significant differences $(P<0.01)$ with healthy control. Bars within the same group with different superscript characters $(\mid,+,+)$ denote significant differences $(P<0.01)$ with day 7 values 
serum total antioxidant capacity levels (mmol/l) in Diabetic rats with $\mathrm{ZnO}$ nanoparticles \& $\mathrm{ZnSO}_{4}$

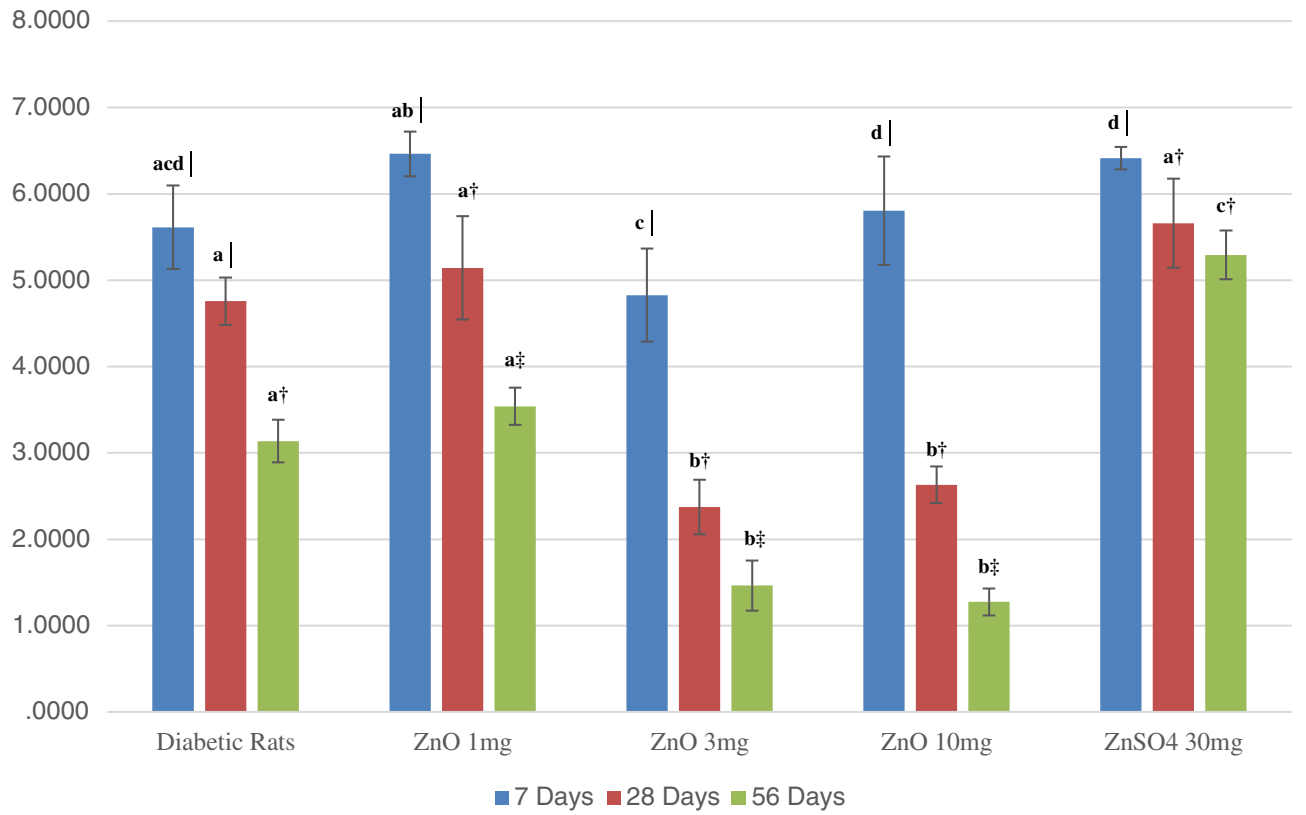

Fig. 2. Effects of $\mathrm{ZnO}$ nanoparticles and $\mathrm{ZnSO}_{4}$ on serum TAC levels (mmol/l) in diabetic rats. Each bar represents mean $\pm \mathrm{SD}$ in each group. Bars within the same color carrying different superscript letters (a-d) denote significant differences $(P<0.01)$ with diabetic control. Bars within the same group carrying different superscript characters $(\mid,+,+)$ denote significant differences $(P<0.01)$ with day 7 values

hydroxyl radicals, act on unsaturated fatty acids of phospholipid components of membranes to produce malondialdehyde, a lipid peroxidation product (40). Such injury to cell membrane finally can lead to cell death. Our results of diabetic rats were in agreement with those of recent studies that demonstrated increase in MDA concentrations by hyperglycemiainduced glucose autooxidation and glycation of proteins $(35,39,41,42)$. Treatment with $\mathrm{ZnO}$ nanoparticles aggravated lipid peroxidation status particularly at the highest dose $(10 \mathrm{mg} / \mathrm{kg})$ in both healthy and diabetic rats, which indicated toxic nature of the nanoparticle. There are a growing number of studies showing that $\mathrm{ZnO}$ nanoparticles can generate ROS and consequently induce lipid peroxidation $(26,27,43)$. We also observed that zinc sulfate protected lipid peroxidation and ROS generation evidenced by a significant reduction of MDA level in diabetic rats. Parallel observations have been reported previously $(35,39,44)$. The generation of ROS and the subsequent induction of oxidative stress are thought to be the predominant mechanism of nanoparticle toxicity $(28,29)$. The amount of ROS generation by engineered nanomaterials is associated with chemical nature of the nanoparticles. Compared to their bulk-size counterparts, engineered nanomaterials possess a small size, high specific surface area, and high surface reactivity leading to the production of higher levels of ROS and induction of oxidative damages (29). Large amounts of ROS could be generated even when only small amounts of $\mathrm{ZnO}$ nanoparticles are amalgamated into cells (28). The key features of nanoparticles are tightly correlated with particle size, and some of them have effects on the interactions between nanomaterials and biomolecules that subsequently affect the nanotoxicological behaviors of nanoparticles (28). In a comparative study between nano- and micrometer size metal oxide, Karlsson and coworkers found that copper oxide nanoparticles were much more toxic in comparison with their micrometer counterparts. However, based on their findings, it cannot be generalized that nanoparticles are always more toxic than micrometer particles (45). Further, in a study, the ability of $\mathrm{ZnO}$ nanoparticles in generation of different ROS was compared to their respective ionic form and results showed that $\mathrm{ZnO}$ nanoparticles hugely release ROS compared to their salt and consistently MDA production by $\mathrm{ZnO}$ nanoparticles was more than zinc sulfate (46). The mechanisms by which zinc protects against lipid peroxidation and ROS generation have not yet been completely elucidated. Prasad and coworkers (2004) studied antioxidant effect of zinc in humans. They found that zinc negatively regulates gene expression of inflammatory cytokines such as TNF- $\alpha$ and IL-1 $\beta$, which are known to generate ROS (47). Zinc has also been proposed to interact with cell membranes to stabilize them against oxidative damages (48).

The antioxidant enzymes, SOD, GSH-Px, and catalase work together to eliminate active oxygen species and prohibit the harmful effects of oxidant molecules on tissues and cells. Small deviations in physiological concentrations of these enzymes may result in defect of body defense system and vulnerability of biomolecules to oxidative damages (49).

It has been claimed that hyperglycemia is able to generate reactive oxygen species, disturb GSH/GSSG balances, and reduce GSH-Px activity by glycolysation in erythrocytes, thus leads to long-term complications of diabetes $(50,51)$. Our findings of decreased activity of erythrocyte GSH-Px in diabetic rats agree with the previous reports. Our data of diabetic rats demonstrated that treatment with zinc sulfate efficiently restored GSH-Px activity in a time-dependent manner. Similar observations have been reported previously (35). Uyoyo 
Ukperoro et al. found that dietary supplementation with $\mathrm{ZnSO}_{4}$ could elevate GSH levels in the liver and kidney of diabetic rats. They concluded that zinc can either increase the biosynthesis of GSH or reduce the oxidative stress leading to less degradation of GSH, or having both effects (44). Consistently, it has been suggested that zinc can bind to sulfhydryl groups and protect them against oxidation (52). With respect to $\mathrm{ZnO}$-receiving animals, we found a significant reduction of GSH-Px activity, at higher doses $(3$ and $10 \mathrm{mg} / \mathrm{kg}$ ). Ali and coworkers reported that $\mathrm{ZnO}$ treatment to fresh water snail significantly depressed GSH-Px activity and its substrate levels (GSH) in a time- and dose-dependent fashion (43). Additionally, under oxidative stress condition, glutathione (GSH) is consumed by the glutathione-related enzymes (such as GSH-Px) to detoxify peroxides produced due to increased lipid peroxidation (53). Therefore, the decreased activities of GSH-Px might be due to overproduction of ROS, especially hydroperoxides by $\mathrm{ZnO}$ nanoparticles and depletion of its substrate. Our data of increased MDA levels supported this hypothesis.

Catalase is ubiquitously present in a wide range of aerobic cell types with the highest activities in mammals being found in liver, kidney, and red blood cells. It reduces the $\mathrm{H}_{2} \mathrm{O}_{2}$ into water and molecular oxygen $\left(\mathrm{O}_{2}\right)$ to prevent cells from oxidative damage (54). Our experiment revealed a significant reduction in $\mathrm{RBC}$ and serum catalase activity in diabetic rats. This finding is consistent with a number of previous studies $(31,39,44)$. It has been reported that hyperglycemia increases hydrogen peroxide production and downregulates CAT gene expression (55). A number of in vitro and in vivo studies have found varying responses of catalase to increased amount of ROS production induced by $\mathrm{ZnO}$. Some of them showed elevated activity $(31,43,56)$, whereas others exhibited suppressed activity $(57,58)$. In our study, although $\mathrm{ZnO}$ nanoparticles could relatively restore catalase activities in diabetic rats, however, severely inhibited the enzyme activity in healthy ones. This finding was indicative of toxic nature of the nanoparticle. The decrease in the activity of catalase in healthy animals may be due to the consumption of this enzyme in converting the $\mathrm{H}_{2} \mathrm{O}_{2}$ into $\mathrm{H}_{2} \mathrm{O}$ and $\mathrm{O}_{2}$ or its low rate of enzyme turnover. Considering the healthy rats, receiving zinc sulfate, we noticed no significant change in catalase activity indicating its safety. Additionally, it could improve CAT activity in diabetic animals. This protective effect of zinc could be related to the antioxidative properties of this metal ion and agree with previous reports $(39,44)$.

Superoxide dismutase (SOD) plays a critical role in neutralizing of ROS and is tightly associated with zinc ions (50). SOD possesses the largest catalytic efficiency of any known enzyme (59). The enzyme catalyzes the partitioning of the toxic superoxide $\left(\mathrm{O}^{2-}\right)$ radical with high proficiency $(50)$. In contrast to previous researches $(31,39)$, we observed raised levels of RBC superoxide dismutase activity in diabetic rats. Further, we found a trend toward increase in the enzyme activity in both healthy and diabetic rats receiving $\mathrm{ZnO}$. These data suggested that $\mathrm{ZnO}$ treatment might result in increasing of ROS generation, which could stimulate SOD activity to cope with this increased oxidative stress. Khan and colleagues' study (2015) may shed light on our work. As mentioned above, they found that toxic superoxide radical formation by $\mathrm{ZnO}$ nanoparticles was much more than $\mathrm{ZnSO}_{4}$. In addition, they observed a dosedependent increase in activity of erythrocyte SOD (46). These data completely match those reported here. Moreover,
Muthuraman and collaborators reported a dose-dependent increase in gene expression and activity of SOD in adipocytes exposed to different concentrations of $\mathrm{ZnO}$ nanoparticles (56). With regard to the animals which were administered with zinc sulfate, we observed normalization of SOD activity. The observed normalization following zinc treatment could be related to the antioxidant potential of this metal ion.

Antioxidant capacity of serum is the primary measure and marker to evaluate the status and potential of oxidative stress in the body (50). In fact, the capacity of known and unknown antioxidants and their synergistic interaction is therefore assessed, thus giving an insight into the delicate balance in vivo between oxidants and antioxidants (60). Our findings showed that the serum TAC of diabetic rats was considerably lower than the healthy control. Some researchers reported the same results about the TAC in diabetic subjects (61-63). The higher doses of $\mathrm{ZnO}$ were found to be highly toxic evidenced by a marked reduction of TAC in diabetic rats. It has been claimed that serum antioxidants can be decreased compared to established normal values as a consequence of free radical production (64). Biological and toxicological behaviors of nanoparticles are associated with their physicochemical and structural properties. In a comparative study of the mechanism of toxicity of zinc oxide and cerium oxide nanoparticles, it was demonstrated that dissolution plays an important role in $\mathrm{ZnO}$-induced cytotoxicity. $\mathrm{ZnO}$ dissociation and release of toxic $\mathrm{Zn}^{2+}$ in the cell culture medium disrupt cellular zinc homeostasis, leading to lysosomal and mitochondria damage and ultimately cell death via generation of ROS and oxidative injury (65).

Zinc sulfate administration did not change serum total antioxidant capacity in healthy rats which indicates no risk of oxidative stress induction. Additionally, $\mathrm{ZnSO}_{4}$ could efficiently help recuperation of TAC, suggesting its potent antioxidant effect. A large number of studies have proved that, zinc functions not only as a nutrient, but also as potent inducer of metallothionein. (66). It is well established that metallothionein has a profound effect on the reduction of oxidative stress induced by the diabetic condition due to the presence of cysteine residues. Overexpression of metallothionein in various metabolic organs has been shown to reduce hyperglycemia-induced oxidative stress, organ-specific diabetic complications, and DNA damage in diabetic experimental animals (66).

In our experiment, the altered activities of erythrocyte antioxidant enzymes as well as raised levels of lipid peroxidation and marked reduction of serum TAC indicated the induction of oxidative stress in rats receiving zinc oxide nanoparticles. Superoxide dismutase has the largest catalytic efficiency in body. Therefore, one possible explanation for the observed alterations of the enzyme activities is that the elevation in SOD activity may be due to compensatory mechanisms by the body to prohibit deleterious effects of oxidative damage caused by the increased amounts of ROS.

\section{CONCLUSION}

Taking together, the results of the study demonstrated that zinc oxide nanoparticle acted as a potent antidiabetic agent evidenced by improved glucose disposal, insulin levels, and zinc status in diabetic rats. However, it is very clear from 
this study that the nanoparticles severely elicited oxidative stress particularly at the higher doses evidenced by the altered erythrocyte antioxidant enzyme activities, increase in MDA production, and marked reduction of serum TAC. Finally, our findings offer that $\mathrm{ZnO}$ nanoparticles, because of the ability to instigate oxidative stress, should be administered together with a potent antioxidant agent to prevent the nanoparticle from induction of oxidative damage. Such determinations should be covered in further researches.

\section{ACKNOWLEDGMENTS}

We would like to express our sincere gratitude and appreciation to Mr. R. Vosough, Mr. H. Jafari-Namin, and Mrs. F. Golmoradi for their tremendous support.

Conflict of interest. This work is part of DVM thesis of Dr. Ali Nazarizadeh numbered 1414, under supervision of Dr. Siamak Asri Rezaie. The authors declare that they have no competing interests.

\section{REFERENCES}

1. Maritim AC, Sanders RA, Watkins JB. Diabetes, oxidative stress, and antioxidants: a review. J Biochem Mol Toxicol. 2003;17(1):24-38.

2. International Diabetic Federation. IDF diabetes atlas (Executive Summary). Sixth edition, Page 11. ISBN: 2-930229-85-3, 2013.

3. Zargar A, Shah N, Masoodi S, Laway B, Dar F, Khan A, et al. Copper, zinc and magnesium level in type-1 diabetes mellitus. Saudi Med J. 2002;23:539-42.

4. Kazi T, Afridi H, Kazi N, Jamali M, Arain M, Jalbani N, et al. Copper, chromium, manganese, iron, nickel, and zinc levels in biological samples of diabetes mellitus patients. Biol Trace Elem Res. 2008;122:1-18.

5. Thompson K, Godin D. Micronutrients and antioxidants in the progression of diabetes. Nutr Res. 1995;15(9):1377-410.

6. Bonnefont-Rousselot $\mathrm{D}$. The role of antioxidant micronutrients in the prevention of diabetic complications. Treat Endocrinol. 2004;3(1):41-52.

7. Vardatsikos G, Pandey N, Srivastava A. Insulino-mimetic and anti-diabetic effects of zinc. J Inorg Biochem. 2013;120:8-17.

8. Prasad A. Zinc: an overview. Nutrition. 1995;11:93-9.

9. Shaker A, Prasad A. Zinc and immune function: the biological basis of altered resistance to infection. Am J Clin Nutr. 1998;68:447-67.

10. Wintergerst E, Maggini S, Hornig D. Contribution of selected trace elements and vitamins to immune function. Ann Nutr Metab. 2007;51:301-21.

11. Lansdown A, Mirastschijiski U, Stubbs N, Scanlon E, Agren M. Zinc in wound healing: theoretical, experimental, and clinical aspects. Wound Repair Reg. 2007;15:2-16.

12. Song Y, Wang J, Li XK, Cai L. Zinc and the diabetic heart. BioMetals. 2005;18(4):325-32.

13. Haase H, Overbeck S, Rink L. Zinc supplementation for the treatment or prevention of disease: current status and future perspectives. Exp Gerontol. 2008;43(5):394-408. doi:10.1016/ j.exger.2007.12.002.

14. Scott D. Crystalline insulin. Biochem J. 1934;28(4):1592-602.

15. Barrett K, Barman S, Boitano S, Brooks H. Ganong's review of medical physiology. McGraw-Hill; 2010. p. 316.

16. Jansen J, Karges W, Rink L. Zinc and diabetes-clinical links and molecular mechanisms. J Nutr Biochem. 2009;20(2009):399-417.

17. X-h T, Shay NF. Zinc has an insulin-like effect on glucose transport mediated by phosphoinositol-3-kinase and Akt in 3T3-L1 fibroblasts and adipocytes. J Nutr. 2001;131(5):1414-20.

18. Eom SJ, Kim EY, Lee JE, Kang HJ, Shim J, Kim SU, et al. $\mathrm{Zn}^{(2+)}$ induces stimulation of the c-Jun N-terminal kinase signaling pathway through phosphoinositide 3-Kinase. Mol Pharmacol. 2001;59(5):981-6.
19. Kim S, Jung Y, Kim D, Koh H, Chung J. Extracellular zinc activates p70 S6 kinase through the phosphatidylinositol 3kinase signaling pathway. J Biol Chem. 2000;275(34):2597984.

20. Walter PL, Kampkotter A, Eckers A, Barthel A, Schmoll D, Sies $\mathrm{H}$, et al. Modulation of FoxO signaling in human hepatoma cells by exposure to copper or zinc ions. Arch Biochem Biophys. 2006;454(2):107-13. doi:10.1016/j.abb.2006.08.016.

21. Wu W, Wang X, Zhang W, Reed W, Samet JM, Whang YE, et al. Zinc-induced PTEN protein degradation through the proteasome pathway in human airway epithelial cells. J Biol Chem. 2003;278(30):28258-63. doi:10.1074/jbc.M303318200.

22. Salata OV. Applications of nanoparticles in biology and medicine. J Nanobiotechnol. 2004;2:3-3. doi:10.1186/1477-3155-2-3.

23. Vandebriel R, De Jong W. A review of mammalian toxicity of ZnO nanoparticles. Nanotechnol Sci Appl. 2012;5:61-71.

24. De M, Ghosh PS, Rotello VM. Applications of nanoparticles in biology. Adv Mater. 2008;20(22):4225-41. doi:10.1002/ adma.200703183.

25. Xia T, Kovochich M, Brant J, Hotze M, Sempf J, Oberley T, et al. Comparison of the abilities of ambient and manufactured nanoparticles to induce cellular toxicity according to an oxidative stress paradigm. Nano Lett. 2006;6(8):1794-807.

26. Sharma V, Singh P, Pandey A, Dhawan A. Induction of oxidative stress, DNA damage and apoptosis in mouse liver after sub-acute oral exposure to zinc oxide nanoparticles. Mutat Res. 2012;745:84-91.

27. Sharma V, Anderson D, Dhawan A. Zinc oxide nanoparticles induce oxidative DNA damage and ROS-triggered mitochondria mediated apoptosis in human liver cells (HepG2). Apoptosis. 2012;17:852-70.

28. Chang Y, Zhang M, Xia L, Zhang J, Xing G. The toxic effects and mechanisms of $\mathrm{CuO}$ and $\mathrm{ZnO}$ nanoparticles. Materials. 2012;5:2850-71.

29. Fu P, Xia Q, Hwang H, Ray P, Yu H. Mechanisms of nanotoxicity: generation of reactive oxygen species. J Food Drug Anal. 2014;22:64-75. doi:10.1016/j.jfda.2014.01.005.

30. Fukui H, Horie M, Endoh S, Kato H, Fujita K, Nishio K, et al. Association of zinc ion release and oxidative stress induced by intratracheal instillation of $\mathrm{ZnO}$ nanoparticles to rat lung. Chem Biol Interact. 2012;198:29-37.

31. Umrani RD, Paknikar KM. Zinc oxide nanoparticles show antidiabetic activity in streptozotocin-induced type 1 and 2 diabetic rats. Nanomedicine (Lond Engl). 2014;9(1):89-104. doi:10.2217/ nnm.12.205.

32. Alkaladi A, Abdelazim AM, Afifi M. Antidiabetic activity of zinc oxide and silver nanoparticles on streptozotocin-induced diabetic rats. Int J Mol Sci. 2014;15(2):2015-23. doi:10.3390/ ijms15022015.

33. Council NR. Nutrient requirements of laboratory animals, fourth revised edition, 1995. Washington, DC: The National Academies Press; 1995.

34. Tamaddonfard E, Farshid AA, Asri-Rezaee S, Javadi S, Khosravi $\mathrm{V}$, Rahman B, et al. Crocin improved learning and memory impairments in streptozotocin-induced diabetic rats. Iran J Basic Medl Sci. 2013;16(1):91-100.

35. Özcelik D, Nazıroglu M, Tunçdemir M, Çelik Ö, Öztürk M, Flores-Arce MF. Zinc supplementation attenuates metallothionein and oxidative stress changes in kidney of streptozotocininduced diabetic rats. Biol Trace Elem Res. 2012;150(1-3):3429. doi:10.1007/s12011-012-9508-4.

36. Nair V, Turner G. The thiobarbituric acid test for lipid peroxidation structure of the adduct with malondialdehyde. Lipids. 1984;19:84-95.

37. Asri Rezaei S, Dalir-Naghadeh B. Evaluation of antioxidant status and oxidative stress in cattle naturally infected with Theileria annulata. Vet Parasitol. 2006;142(1-2):179-86. doi:10.1016/j.vetpar.2006.05.033.

38. Miao X, Sun W, Fu Y, Miao L, Cai L. Zinc homeostasis in the metabolic syndrome and diabetes. Front Med. 2013;7(1):31-52. doi:10.1007/s11684-013-0251-9.

39. Duzguner V, Kaya S. Effect of zinc on the lipid peroxidation and the antioxidant defense systems of the alloxan-induced diabetic rabbits. Free Radic Biol Med. 2007;42(10):1481-6. doi:10.1016/ j.freeradbiomed.2007.02.021. 
40. Mansour S, Mossa A. Lipid peroxidation and oxidative stress in rat erythrocytes induced by chlorpyrifos and the protective effect of zinc. Pestic Biochem Physiol. 2009;93:43-39.

41. Tang Y, Yang Q, Lu J, Zhang X, Suen D, Tan Y, et al. Zinc supplementation partially prevents renal pathological changes in diabetic rats. J Nutr Biochem. 2010;21(3):237-46. doi:10.1016/ j.jnutbio.2008.12.010.

42. El-Missiry MA, El Gindy AM. Amelioration of alloxan induced diabetes mellitus and oxidative stress in rats by oil of eruca sativa seeds. Ann Nutr Metab. 2000;44(3):97-100.

43. Ali D, Alarifi S, Kumar S, Ahamed M, Siddiqui MA. Oxidative stress and genotoxic effect of zinc oxide nanoparticles in freshwater snail Lymnaea luteola L. Aquat Toxicol. 2012;124-125:8390. doi:10.1016/j.aquatox.2012.07.012.

44. Uyoyo Ukperoro J, Offiah N, Idris T, Awogoke D. Antioxidant effect of zinc, selenium and their combination on the liver and kidney of alloxan-induced diabetes in rats. Mediterr J Nutr Metab. 2010;3(1):25-30. doi:10.1007/s12349-009-0069-9.

45. Karlsson HL, Gustafsson J, Cronholm P, Möller L. Sizedependent toxicity of metal oxide particles - a comparison between nano- and micrometer size. Toxicol Lett. 2009;188:112-18.

46. Khan M, Naqvi AH, Ahmad M. Comparative study of the cytotoxic and genotoxic potentials of zinc oxide and titanium dioxide nanoparticles. Toxicol Rep. 2015. doi:10.1016/ j.toxrep.2015.02.004.

47. Prasad A, Bao B, BECK FWJ, Kucuk O, Sarkar F. Antioxidant effect of zinc in humans. Free Radic Biol Med. 2004;37(8):1182-90.

48. Bettger WJ, O'Dell BL. A critical physiological role of zinc in the structure and function of biomembranes. Life Sci. 1981;28:1425-38.

49. Goel A, Dani V, Dhawan D. Protective effects of zinc on lipid peroxidation, antioxidant enzymes and hepatic histoarchitecture in chlorpyrifos-induced toxicity. Chem Biol Interact. 2005;156:131-40.

50. Tiwari BK, Pandey KB, Abidi AB, Rizvi SI. Markers of oxidative stress during diabetes mellitus. J Biomark. 2013;2013:8. doi:10.1155/2013/378790.

51. Bonnefont-Rousselot D, Bastard JP, Jaudon MC, Delattre J. Consequences of the diabetic status on the oxidant/antioxidant balance. Diabetes Metab. 2000;26(3):163-76.

52. Bettger WJ. Zinc and selenium, site-specific versus general antioxidant. Can J Physiol Pharmacol. 1993;71:721-4.

53. Cathcart Iii RF. Vitamin C: the nontoxic, nonrate-limited, antioxidant free radical scavenger. Med Hypotheses. 1985;18:61-77.

54. Deisseroth A, Dounce AL. Catalase: physical and chemical properties, mechanism of catalysis, and physiological role. Physiol Rev. 1970;50(3):319-75.
55. Patel H, Chen J, Das K, Kavdia M. Hyperglycemia induces differential change in oxidative stress at gene expression and functional levels in HUVEC and HMVEC. Cardiovasc Diabetol. 2013;12(1):142.

56. Muthuraman P, Ramkumar K, Kim D. Analysis of dosedependent effect of zinc oxide nanoparticles on the oxidative stress and antioxidant enzyme activity in adipocytes. Appl Biochem Biotechnol. 2014;174(8):2851-63. doi:10.1007/s12010014-1231-5.

57. Hu CW, Li M, Cui YB, Li DS, Chen J, Yang LY. Toxicological effects of $\mathrm{TiO} 2$ and $\mathrm{ZnO}$ nanoparticles in soil on earthworm Eisenia fetida. Soil Biol Biochem. 2010;42(4):586-91. doi:10.1016/j.soilbio.2009.12.007.

58. Sharma V, Shukla RK, Saxena N, Parmar D, Das M, Dhawan A. DNA damaging potential of zinc oxide nanoparticles in human epidermal cells. Toxicol Lett. 2009;185:211-8.

59. Kriegel T, Schellenberger W. In: Löffler G, Petrides PE, Heinrich PC, editors. Biochemie und pathobiochemie. Berlin: SpringerLehrbuch; 2007.

60. Ghiselli A, Serafini M, Natella F, Scaccini C. Total antioxidant capacity as a tool to assess redox status: critical view and experimental data. Free Radic Biol Med. 2000;29(11):1106-14.

61. Lodovici M, Giovannelli L, Pitozzi V, Bigagli E, Bardini G, Rotella CM. Oxidative DNA damage and plasma antioxidant capacity in type 2 diabetic patients with good and poor glycaemic control. Mutat Res Fundam Mol Mech Mutagen. 2008;638(12):98-102. doi:10.1016/j.mrfmmm.2007.09.002.

62. Hisalkar P, Patne A, Karnik A, Fawade M, Mumbare S. Ferric reducing ability of plasma with lipid peroxidation in type 2 diabetes. Age (Yr). 2012;42:8.70.

63. Catanzaro O, Capponi JA, Michieli J, Labal E, Di Martino I, Sirois P. Bradykinin B1 antagonism inhibits oxidative stress and restores $\mathrm{Na}^{+} \mathrm{K}^{+}$ATPase activity in diabetic rat peripheral nervous system. Peptides. 2013;44:100-4. doi:10.1016/ j.peptides.2013.01.019.

64. Polidori MC, Stahl W, Eichler O, Niestroj I, Sies H. Profiles of antioxidants in human plasma. Free Radic Biol Med. 2001;30(5):456-62.

65. Xia T, Kovochich M, Liong M, Mädler L, Gilbert B, Shi H, et al. Comparison of the mechanism of toxicity of zinc oxide and cerium oxide nanoparticles based on dissolution and oxidative stress properties. ACS Nano. 2008;2(10):2121-34. doi:10.1021/ nn800511k.

66. Islam MDS, Loots DT. Diabetes, metallothionein, and zinc interactions: a review. BioFactors. 2007;29(4):203-12. doi:10.1002/ biof. 5520290404. 